\title{
Readiness Analysis of Electronic Medical Record Implementation at Dinda Tangerang Hospital Using Correlational Method
}

\author{
Diana Kusriyanti, Supriyantoro, and Budi Matuwi
}

\section{ABSTRACT}

The electronic medical record (EMR) known today is not a new system in the documentation of patient medical records. Electronic Medical Record is a system that contains the patient's health and disease history, diagnostic test results, other medical data, and treatment cost information. In Indonesia it is known as Rekam Medis Elektronik (RME).

In accordance with the vision of Dinda Tangerang Hospital to be a quality hospital and trusted by all levels of society, it is appropriate to use technology in its medical record services. Where currently the medical record unit of Dinda Tangerang Hospital still uses Paper Based Medical Record. So, a readiness analysis is required to switch to EMR. This research uses quantitative research method with correlational research design that aims to know the readiness of Dinda Tangerang Hospital in applying EMR. The departments studied are the medical department, the medical support department, and the medical records unit. The most powerful relationship between a variable with an $R$ value is 0.632. The value is in the criteria of correlation coefficient value of $0.51-0.75$ which means there is a strong relationship between the organization and monitoring and collaboration. while the readiness analysis of Dinda Tangerang Hospital to apply electronic medical records is in range IV and can be said to be ready.

Keywords: Electronic Medical Record, Monitoring, Collaboration, Readiness Analysis.

\author{
Submitted : June 09, 2021 \\ Published : July 02, 2021 \\ ISSN: 2507-1076 \\ DOI: $10.24018 /$ ejbmr.2021.6.4.915 \\ Diana Kusriyanti * \\ Master of Hospital Administration \\ Programme, Esa Unggul University, \\ Jakarta, Indonesia. \\ (e-mail: dekana14250@gmail.com) \\ Budi Matuwi \\ Master of Hospital Administration \\ Programme, Esa Unggul University, \\ Jakarta, Indonesia. \\ (e-mail: budimatuwi@esaunggul.ac.id) \\ Supriyantoro \\ Master of Hospital Administration \\ Programme, Esa Unggul University, \\ Jakarta, Indonesia. \\ (e-mail: priyantoro11@gmail.com) \\ *Corresponding Author
}

\section{INTRODUCTION}

The electronic medical record (EMR) known today is not a new system in the documentation of patient medical records. Electronic Medical Record is a system that contains the patient's health and disease history, diagnostic test results, other medical data, and treatment cost information. EMR will improve health care services by providing patient care, but healthcare managers will have to spend a considerable fee to provide information technology systems to use EMR. Implementation cannot happen suddenly but takes a long time. EMR is already used in various hospitals in the world as a substitute or complement to paper-shaped health records. In Indonesia it is known as Rekam Medis Elektronik (RME). Since the development of e-Health, EMR has become a center of information in the hospital's information system. EMR has started to be used in several hospitals in Indonesia, especially hospitals with foreign investors (PMA) [1].

Medical record unit, in a means of health care is a busy unit and desperately needs high performance from its officers. Although medical records officers are not directly involved in the patient's clinical, the information recorded on the medical record is an important part of the health service. But sometimes the importance of this work is not understood by medical personnel, hospital administration staff and other employees, so the officers of the medical records unit often feel minded. This is further exacerbated by the problem of limited funds, resulting in a lack of effort in improving the ability of resources that ultimately difficult to achieve effective and efficient medical record services.

EMR is used to record demographic data, disease history, treatment, actions, up to payment in registration, polyclinics, inpatient wards, support units, and cashiers [2]. Currently, EMR is still in the development stage to fit the needs and expectations of users. Users are an important aspect to realize the ideal EMR [3]. The quality of medical records will describe the quality of health services held. One indicator of the quality of hospital services is the quality of medical record services. This indicator is a minimal indicator that should be implemented in most hospitals regardless of the type of hospital [4]. In this case, researchers chose Dinda Tangerang Hospital as one of the rapidly growing Type $\mathrm{C}$ hospitals in the Tangerang area. In accordance with the vision of Dinda Tangerang Hospital to be a quality hospital and trusted by all levels of society, it is appropriate to use technology in its medical record services. Where currently the medical record unit of Dinda Tangerang Hospital still uses Paper Based Medical Record. Looking at the current condition and the results of the researchers' pre-survey through questionnaires and interviews, it can be said that Dinda Tangerang Hospital will need more medical record storage space and longer time 
to search for medical records. And it will automatically extend the waiting time of registration, outpatient, inpatient, and other medical support services resulting in the failure to achieve the quality of service as expected. In addition, the limited workforce in the medical records unit is not comparable to its workload so there are often errors such as duplication of medical record numbering. Coupled with an un-integrated medical record reporting system. So, the application of electronic medical records is the right choice and will greatly help the performance of Dinda Tangerang Hospital services. Therefore, it is necessary to analyze the readiness of the application of electronic medical records at Dinda Hospital Tangerang. Readiness analysis can be done by several readiness methods and researchers choose correlational methods to assess the readiness of the application of medical records at Dinda Tangerang Hospital.

\section{THEORETICAL STUDIES}

\section{A. Medical Record}

According to Edna K Huffman medical records are files stating who, what, why, where, when and how the services that a patient is treated during treatment or treatment [5].

According to Waters and Murphy medical records are compendium (overview) that contains information about the patient's condition during treatment or during health care [6].

In his book entitled "Legal Aspect of Medical Record" Hayt and Hayt defines medical records as follows:

"A Medical record is the compilation of the partinent fact of the patient's life history, his illness, and treatment. In a larger sense the medical record is a compilation of scientific data derived from many and available for various uses, personal and impersonal, to serve the patiens was treated, the science of medce, and society as awhole." (Hayt and Hayt, 1964: 1). According to Hayt and Hayt, a medical record is a set of facts related to the patient's history/life history, illness, nurse/treatment. In a broader (broader) sense medical records are a collection of scientific data from many sources, coordinated on a single document and provided for a wide variety of uses, personnel and impersoanl, to serve patients treated, treated, medical science, and society as a whole [2].

\section{B. Medical Record Implementation}

Some hospitals in Indonesia are also now starting to switch from paper-based medical records to electronic medical records. Research related to this is still small. In addition to the need for adaptation process to electronic medical records, hospitals and other health facilities need to anticipate problems that may arise from the use of electronic medical records. If the use of electronic medical records can be utilized properly, it is expected to facilitate health services to be more efficient and can improve patient satisfaction in health services. The organization's readiness analysis in the application of electronic medical records is to conduct an EMR pre-implementation readiness assessment that will help top management to choose whether to start EMR implementation or implement a cheaper initial step, which will prepare the organization to anticipate changes. The process of analyzing the readiness of EMR implementation can be done to be able to determine the "road map" and provide an overview of whether to continue on electronic health records (DOQ-IT, 2009). To determine the road map and sustainability of the electronic medical record development program at Dinda Tangerang Hospital, an analysis of the organization's readiness to support leaders, organizations and Change Targets is also needed. The application of EMR certainly cannot be separated with the application of information technology. Explained that the use of health information technology (IT) and the need for health IT for coordination of care are interconnected, consisting of monitoring, notification, collaboration, reporting, interoperability [7].

\section{Monitoring}

In the 3rd monograph series, UNESCO Regional Office for Education in Asia and The Pasific, it is explained that monitoring is a routine effort to identify the implementation of various components of the program as planned, the time of implementation of the program as scheduled, and progress in achieving the objectives of the program. Monitoring activities for improvement while the work is still running, whether it is according to planning or not. In this case ensure that the working procedures of the medical records unit are well implemented. The function of monitoring in sustainable management is to provide recommendations to perform corrective actions to the leadership of health services. If then the corrective action is carried out, then the control function will be carried out completely.

Monitoring results that have been analyzed and processed can be used as information that can be easily understood by the manager / head of medical records for the basis of decision making is not advanced, both concerning ongoing activities and future activities, including improving the quality of medical record services through electronic medical records.

Collaboration is a process of participation of several people or groups of organizations to work together to achieve certain results [8].

In EMR this collaboration takes place between nurses, doctors, management in communicating to provide health services for patients.

Variable Collaboration is a combination of communication between management, medical personnel, paramedics and patients. Collaboration will optimize patient care coordination. With an electronic medical record of treatment activities can be coordinated between the hospital and the patient. For example, patients who have registered with one of the doctors during the specified hours of practice then if there is a change in the hours of arrival of the doctor eating the hospital can coordinate its management to inform the change in the doctor's arrival hours. Or vice versa if the patient wants to make changes to the schedule of his visit. Similarly, if it is necessary to transfer patients to other healthcare facilities then with the availability of electronic medical records, collaboration will be easier to do and access So, with an electronically based hospital information system the treatment plan can be conditioned effectively to support team-based care [9].

\section{Readiness Analysis}

According to The Great Dictionary of Indonesian Analysis is the decipher EMRnt of a subject over its various parts and the study of the passage itself as well as the relationship 
between parts to obtain a proper understanding and understanding of the overall meaning.

According to Jamies Drever Readiness is Preparedness to respond or react meaning Readiness is a willingness to respond or react.

According to Tondike readiness is a prerequisite for learning to the next stage.

From some of the above opinions, it can be concluded that the readiness of the application of electronic medical records is an initial condition of an organization that will apply electronic medical records that make it ready to provide responses that exist on him in achieving certain goals.

The readiness of an organization in implementing EMR is adopted from research conducted, which consists of 4 (four) related variables, namely:

- Attribute changes;

- Leader support;

- Organization;

- Change Target.

Of the 4 variables, researcher used 3 variables studied, namely: support leaders, organization and Change Target. [7]

\section{E. Leader Support}

Leadership is the ability to influence teams to achieve goals. Leadership as attentive to people when it comes to providing subordinates with support, mentoring and coaching [10].

A leader's ability to motivate, communicate and build a team is a powerful predictor of successful change [11]. In addition, the ability of leaders who have a strong and positive influence on innovation trends can influence the process of initiation of change [12].

The readiness of the organization in implementing a program in this case the application of electronic medical records must be determined by a leader himself so that he can achieve good performance quickly, appropriately, and efficiently, but still have a good relationship with his employee [13].

\section{Organization}

Information technology (IT) does offer many advantages over the use of paper for storage and retrieval of patient data. But to implement EMR encountered several challenges, including infrastructure and structure problems, information technology problems, lack of need assessment, cultural problems, high costs of software, hardware, and data exchange standards [14]. Therefore, it is necessary to conduct a readiness assessment before the implementation of EMR. This will help identify priority processes and scales, as well as help the establishment of operational functions to support optimization of EMR implementation [15]. For EMR implementation only need to be added EMR application software. But keep in mind before installing the app, users should be involved in the design. Because users must have a view and hope how the application can make it easier rather than harder for them. If necessary, can be in the form of a special team for that matter. Another consideration is that because each doctor has differences in terms of work speed and data entry time, this makes EMR function should be made as flexible as possible in terms of navigation, personalization, customization, access to several patients at once, delegation of responsibilities between medical personnel, data variation and visualization [16]. Of course, the overall readiness requires a budget that is not small so that the organization must prepare accurately how much budget is needed in the implementation of EMR.

\section{F. Change Target}

Research literature in the field of change management has established that Individual Readiness for change (IRFC) is one of the most significant factors for successful implementation of organizational change.

According to the researchers, ignoring the vital role of individuals in the process of change, causes failure or difficulty in implementing many change initiatives [17]. Failure of change programs to achieve desired results is often associated with employee resistance to change is essential to achieve the organization's goals.[18] Individuals in an organization are the target of changes that will later implement programs prepared by the organization.

\section{METHOD}

The sample in this study was the entire EMR-related population at Dinda Tangerang Hospital that met the criteria of inclusion and exclusion of 145 people (Purposive Sampling).

The types of instruments used for data retrieval are by interviews, questionnaires, and staffing data. In this study, a tool to collect data using a structured questionnaire with closed questions is a question that is likely the answer has been determined in advance and respondents are not given the opportunity to give other answers.

The scale of this study is the scale of ordinal measurement and measurement design used in this study is Likert scale to see the relationship between variables and Guttman scale to see the readiness level of Dinda Tangerang Hospital in the application of electronic medical records.

\section{A. Data Analysis}

This research is a nonparametric research by using ordinal data as data input so that researchers assume that the data studied is abnormal so that the data analysis used is Spearman Rank (Spearman Rho) test for the relationship between variables (questionnaire I).

The data analysis technique used for the Guttman Scale uses the Three Box Methode, which is created in the form of a checklist, where answers can be made highest scores of one and zero lows.

The hypothesis testing in this study used multiple correlation tests.

\section{B. Research Hypothesis}

The draft hypotheses proposed in this study are as follows:

H1: There is a relationship between monitoring and the support of leaders in emr implementation.

$\mathrm{H} 2$ : There is a relationship between monitoring and organization in emr implementation.

H3: There is a relationship between monitoring and Change Target in EMR implementation.

H4: There is a relationship between collaboration and dreamer support in EMR implementation.

H5: There is a relationship between collaboration and organization in emr implementation. 
H6: There is a relationship between collaboration and Change Target in EMR implementation.

H7: There is a relationship between monitoring and collaboration with the support of leaders, organizations, and targets for changes in EMR implementation.

H8: Dinda Hospital ready to apply EMR.

\section{RESULT}

The questionnaires that were completed and collected were 134 questionnaires from 145 questionnaires distributed. Female respondents were seen more than $67.2 \%$ of male respondents, which is about 92 respondents out of a total of 134 respondents while male respondents only $31.3 \%$ (42 respondents). Based on age, the characteristics of respondents at Dinda Tangerang Hospital were obtained by $67.9 \%$ aged between 16-30 years, while the rest were over 31 years old. So, it can be said that respondents at Dinda Tangerang Hospital are at a productive age. Respondents who have a higher education level of undergraduates of $45.5 \%$ and the remaining $32.8 \%$ have academies education level, $17.9 \%$ are specialists, and $3.0 \%$ are High School (SMA). The method chosen to test the validity of relationships between variables is the corrected item-total correlation method and all variables obtained in questionnaire I and kuesioer II are valid. As for the reliability test (questionnaire I) in this study using Cronbach Alpha, where the value of Cronbach Alpha > 0.60 so that all variables are said to be reliable.

For readiness analysis (questionnaire II) researchers used KR20 reliability test (Kuder Richardson). In this study obtained a value of KR $>0.6$ so that it can be reliable.

The data analysis technique used by questionnaire $\mathrm{I}$ in this study was Spearman Rank Analysis. After statistical tests are carried out, the data obtained is processed again using multiple correlation tests using the SPSS program.

\section{A. Spearman Rank Analysis}

\begin{tabular}{|c|c|c|}
\hline & arman rho & Leader Support \\
\hline \multirow{3}{*}{ Monitoring } & Correlation Coefficient &, $440 * *$ \\
\hline & Sig. (2-tailed) &, 000 \\
\hline & $\mathrm{N}$ & 134 \\
\hline \multirow{4}{*}{ Collaboration } & Correlation Coefficient &, $438 * *$ \\
\hline & Sig. (2-tailed) &, 000 \\
\hline & $\mathrm{N}$ & 134 \\
\hline & Spearman rho & Organization \\
\hline \multirow{3}{*}{ Monitoring } & Correlation Coefficient &, $627 * *$ \\
\hline & Sig. (2-tailed) &, 000 \\
\hline & $\mathrm{N}$ & 134 \\
\hline \multirow{4}{*}{ Collaboration } & Correlation Coefficient &, $550 * *$ \\
\hline & Sig. (2-tailed) &, 000 \\
\hline & $\mathrm{N}$ & 134 \\
\hline & Spearman rho & Change Target \\
\hline \multirow{3}{*}{ Monitoring } & Correlation Coefficient &, $214 * *$ \\
\hline & Sig. (2-tailed) &, 013 \\
\hline & $\mathrm{N}$ & 134 \\
\hline \multirow{3}{*}{ Collaboration } & Correlation Coefficient &, $320 * *$ \\
\hline & Sig. (2-tailed) &, 000 \\
\hline & $\mathrm{N}$ & 134 \\
\hline
\end{tabular}

\section{B. The Relationship between Monitoring (X1) and Leader Support (Y1)}

From the output above, a correlation coefficient of 0.440 is obtained. That is, the level of relationship strength (correlation) between monitoring variables and leader support is 0.440 or strong enough. An asterisk (**) means a significant correlation to a significance of 0.000 .

Based on the output above, it is known the value of significance or sig. (2-tailed) is 0.000 because of the sig value. (2-tailed) $=0.000<\alpha=5 \%$ or $\alpha=1 \%$ then that means there is a significant relationship (meaning) between the monitoring variable and the leader support.

\section{The Relationship between Monitoring (X1) and Organization (Y2)}

From the output above, a correlation coefficient of 0.627 is obtained. That is, the level of relationship strength (correlation) between monitoring variables and organization is 0.627 or strong. An asterisk (**) means a significant correlation to a number of significances of 0.013 .

Based on the output above, it is known the value of significance or sig. (2-tailed) is 0.013 because of the sig value. $(2$-tailed $)=0.013<\alpha=5 \%$ or $\alpha=1 \%$ then it means there is a significant relationship (meaning) between the monitoring variable and the organization.

\section{The Relationship between Monitoring (X1) and Change Target (Y3)}

From the output above, a correlation coefficient of 0.214 is obtained. That is, the level of strength of the relationship (correlation) between the monitoring variable and the Change Target is 0.214 or very weak. An asterisk (*) means a significant correlation to a number of significances of 0.000 .

Based on the output above, it is known the value of significance or sig. (2-tailed) is 0.000 because of the sig value. (2-tailed) $=0.000<\alpha=5 \%$ or $\alpha=1 \%$ then that means there is a significant relationship (meaning) between the monitoring variable and the Change Target.

\section{E. The Relationship between Collaboration (X2) and Leader Support (Y1)}

From the output above, a correlation coefficient of 0.438 is obtained. That is, the level of relationship strength (correlation) between collaboration variables and organizations is 0.438 or strong enough. An asterisk (**) means a significant correlation to a significance of 0.000 .

Based on the output above, it is known the value of significance or sig. (2-tailed) is 0.000 because of the sig value. $(2$-tailed $)=0.000<\alpha=5 \%$ or $\alpha=1 \%$ then it means there is a significant relationship (meaning) between collaboration variables with leader support.

\section{F. The Relationship between Collaboration (X2) and Organization (Y2)}

From the output above, a correlation coefficient of 0.550 is obtained. That is, the level of relationship strength (correlation) between collaboration variables and organizations is 0.550 or strong. An asterisk (**) means a significant correlation to a significance of 0.000 .

Based on the output above, it is known the value of significance or sig. (2-tailed) is 0.000 because of the sig value. $(2$-tailed $)=0.000<\alpha=5 \%$ or $\alpha=1 \%$ then it means there is a significant relationship (meaning) between collaboration variables and organizations. 


\section{G. The Relationship between Collaboration (X2) and Change Target (Y3)}

From the output above, a correlation coefficient of 0.320 is obtained. That is, the level of relationship strength (correlation) between collaboration variables and Change Targets is 0.320 or strong enough. An asterisk (**) means a significant correlation to a significance of 0.000 .

Based on the output above, it is known the value of significance or sig. (2-tailed) is 0.000 because of the sig value. (2-tailed) $=0.000<\alpha=5 \%$ or $\alpha=1 \%$ then there is a significant relationship (meaning) between the collaboration variable and the Change Target.

H. The Relationship between Monitoring (X1) and Collaboration (X2) with Leader Support (Y1), Organization (Y2) and Change Target (Y3).

For the relationship of two independent variables with three dependent variables simultaneously shown in the multiple correlation test table.

Spearman Rank table found that monitoring and collaboration variables have the strongest relationship with organizational variables so that it can be said that the role of the organization is most related to the running of monitoring and collaboration between users of medical records at Dinda Hospital Tangerang.

\section{DISCUSSION RESPONDENT CHARACTERISTICS}

The results of research on the readiness analysis of EMR implementation in Dinda Tangerang Hospital using correlational methods are expected to help and provide hospital input to know the readiness of EMR implementation and what needs to be improved readiness. From the respondents' answers, input, or feedback on hospital readiness in implementing EMR was obtained.

\section{A. Respondents Perception of Monitoring}

From the results of the study, $44.8 \%$ of respondents stated that the accuracy of patient data input is good. $55.2 \%$ of respondents stated that RM officers have done their work in accordance with the SOP well. And 50\% of RM service waiting times have been sufficiently met. The way hospitals responded to complaints from RM users was felt well by $53.7 \%$ of respondents. For supervision so that RM is not scattered is rated good by $44 \%$ of respondents. $50.7 \%$ of respondents stated that the ability of RM staff not to make errors in inputting patient data is good. This is in accordance with the opinion of Hameed et al, 2008 that an electronic medical record-keeping system that will help patients with monitoring more effectively. With electronic medical records, the search for patient data is made easier and helps doctors and nurses in managing the patient's medical records as well as the help of doctors and nurses in making quick decisions.

Spearman correlation test between organizational readiness obtained a strong enough correlation result so that monitoring sufficiently affects the readiness of organizations applying EMR. These results are in accordance with research conducted which states the use of health information technology (IT) and the need for health IT are interconnected.

\section{B. Respondents Perception of Collaboration}

From the results of the study obtained $53.0 \%$ of respondents stated that communication between RM users to date is good. $61.9 \%$ of respondents thought that management's communication with the doctor regarding the agreement with the patient was well established. $52.2 \%$ of respondents thought that patients were satisfied with the coordination provided by the hospital. Cooperation between sections to facilitate the search for RM data was felt by respondents quite well (43.3\%). And the way management in providing RM services in accordance with the waiting time is good with a percentage of respondents $49.3 \%$. This supports green et al's opinion that cooperation between nurses, doctors, and technology specialists is recommended to develop an effective EMR system.

\section{Respondents Perception of Leader Support}

A total of $54.5 \%$ of respondents agreed that the hospital leadership had well understood the benefits of EMR. 56.0\% of respondents agreed that the leadership would facilitate the development of IT personnel competencies from SIMRS. But respondents found $46.3 \%$ were undecided on whether the leadership had budgeted special funds for the development of SIMRS. However, respondents argued that the leadership was able to choose vendors who have good capabilities in IT technology as much as $50.7 \%$. For the special budget for simrs from depth interviews conducted by researchers with the head of Dinda Tangerang Hospital, it is obtained that funds have been budgeted before the COVID-19 pandemic but are currently being allocated for handling the impact of the COVID19 pandemic.

\section{Respondents Perception of The Organization}

A total of $35.1 \%$ of respondents think the current internet speed is adequate. $42.5 \%$ of respondents rated the quality of SIMRS software used today to facilitate the work and needs of its users is good. For the assessment of respondents' ability to use and access EMR obtained $44.85 \%$ good. For the assessment of respondents to the hospital whether it has staff / employees / doctors / specialists who are competent in emr operations obtained $51.5 \%$ good. Respondents as much as $41.8 \%$ considered that the infrastructure owned by the hospital was sufficient in supporting the implementation of EMR. There are still many challenges in the development of SIMRS infrastructure where in implementing EMR there are several challenges, including infrastructure and structure problems, information technology problems, lack of need assessment, cultural problems, high software costs, hardware, and data exchange standards.

\section{E. Respondents Perception of Change Targets}

From this study, respondents mostly agreed on the importance of choosing human resources that have an adequate level of education in the application of EMR (64.2\%). Respondents also agreed that RM users should have discipline to use RM wisely by $50.0 \%$. This was stated by several researchers [17] in the research literature in the field of change management that individual readiness for change (IRFC) is one of the most significant factors in the successful implementation of organizational change.

To analyze the readiness of researchers poured several related indicators in questionnaire II. Where in questionnaire 
II was obtained most of the respondents, $82.1 \%$ had known about electronic medical records. This relates to the respondent's already quite high level of education with $45.5 \%$ being undergraduate. Half of respondents also used electronic medical records $(50.0 \%)$ so that this will facilitate the implementation of electronic medical records. Although later it is necessary to develop further skills. $94.8 \%$ of respondents also agreed that electronic medical records are more effectively used. Especially useful to cut service waiting times $(91.8 \%)$. But respondents as SIMRS users still felt that the internet in Dinda Tangerang Hospital was not adequate (51.5\%). A total of $94.8 \%$ of respondents felt that the software currently used needed to be improved even better. It is the duty of management and leaders to improve internet services at Dinda Tangerang Hospital which will certainly affect the quality of hospital services and patient satisfaction. For medical records personnel, respondents stated that it is quite reliable $(82.8 \%)$. So, respondents largely agreed that the performance of medical record services is now good (84.3\%). Almost all respondents (97\%) agreed Dinda Tangerang Hospital it's time to switch to electronic medical records. And they felt management was reliable enough to implement electronic medical records $(72.4 \%)$. So, it can be said that SIMRS is currently very helpful to respondents in their work (94.8\%).

Realizing the implementation of EMR, previously required the process of migrating paper medical records to EMR that is with a series of processes that begin with the introduction of EMR and its benefits, training the use of EMR on users (users) so that they are able to use when providing services to patients. This will be easier to apply to Dinda Tangerang Hospital because from the research the users already understand the implementation of EMR.

\section{CONCLUSIONS, IMPLICATIONS AND SUGGESTIONS}

From the above reviews can be concluded several things in this study:

- $\quad$ Monitoring has a relationship to the support of leaders in implementing EMR.

- Monitoring has a relationship with the organization in implementing EMR.

- Monitoring has a relationship to the Change Targets in the readiness of EMR implementation.

- Collaboration has a relationship to the support of leaders in implementing EMR.

- Collaboration has a relationship with the organization in implementing EMR.

- Collaboration has a relationship to the target of change in implementing EMR.

- $\quad$ Monitoring and collaboration has a relationship to the readiness of the organization in implementing EMR.

- Dinda Tangerang Hospital is ready to implement EMR with a score index of 121.4.

From the research data obtained both monitoring and collaboration variables have the strongest relationship with the organization. While the lowest value is obtained in connection with the Change Target. While the readiness of Dinda Tangerang Hospital to apply electronic medical records is in range III and can be said to be ready.

\section{ACKNOWLEDGMENT}

On this occasion the author thanked:

1. Dr. Ir. Arief Kusuma Among Praja, MBA., IPU, as rector of Esa Unggul University.

2. Dr. Aprillita Rina Yanti Eff, M.Biomed, Apt as Dean of the Faculty of Health Sciences

3. Dr. Rokiah Kusumapradja, SKM, MHA as Head of Master of Administration Study Program of Esa Unggul University Hospital who has provided time, energy, and mind in the study of this thesis.

4. Dr. dr. Supriyantoro, Sp.P, MARS and Budi Matuwi, MT as supervisors who have taken the time, place, energy, mind, and patience in providing guidance and input in the preparation of this thesis.

5. The Dinda Tangerang Hospital that has helped a lot in trying to obtain the data I need.

6. My children (Sasya, Abel, Ahza), my mother and my dear family (Mas Bayu, Mbak Nur, my nephews) who have provided prayer and moral support.

7. Dr. Ichsanuddin Noorsy, BSc, SH, MSi who has given a lot of knowledge and spirit not to give up.

8. My colleagues and friends who have helped me a lot in providing encouragement, support, and input in completing this thesis.

\section{REFERENCES}

[1] Kalogriopoulos, N., Baran, J., Nimunkar, A., and Webster, J. 2009 Electronic medical record systems for developing countries: review. Annu. Int. Conf. IEEE Eng. Med. Biol. Soc. 2009, 1730-1733. doi:10.1109/IEMBS.2009.5333561.

[2] Hayt, Emanuel and Hayt, Jonathan, 1964, Legal Aspect of Medical Record, Physician's Record Company, Illinois, USA.

[3] N. Shaw, "The role of the professional association: a grounded theory study of electronic medical records usage in ontario, canada," International Journal of Information Management, vol. 34, no. 2, pp. 200-209, 2014.

[4] Rizky Amaliah, Tamri. Jurnal Kesehatan Masyarakat, Vol. 2, No. 1 April 2018. http://ejournal.urindo.ac.id/index.php/jukmas.

[5] Huffman Edna K., 1994, Health Information Management, Tenth Edition, Physician's Record Company, Berwyn, Illinois.

[6] Waters, K. A. and Murphy, G. F. (1979), Medical Records in Health information, Germantown, Maryland: Aspen Systems Corporation.

[7] Holt, D.T., Armenakis, A.A., Field, H.S. and Harris, S.G. (2007), "Readiness for organizational change: the systematic development of a scale", The Journal of Applied Behavioural Science, Vol. 43, No. 2, pp. 232-255

[8] Kusnandar, Fizzanty, dan Trina. 2013. Tipology, Effectiveness, And Principal Elements in International Research Collaboration: Case StudiesOf LIPI's International Research Projects. Warta KIML. Vol. 11, no.2, Pusat Penelitian Perkembangan Iptek, LIPI.

[9] Richardson, J.E., Vest, J.R., Green, C.M., Kern, L.M., Kaushal, R. dan HITEC Investigators. (2015). A needs assessment of health information technology for improving care coordination in three leading patientcentered medical homes. J Am Med Inform Assoc, 22(4), 815820 .

[10] Bass, B.M. (1998), Transformational Leadership: Industrial Millitary.

[11] Gilley, A., McMillan, H. and Gilley, J. (2009), "Organizational change and characteristics of leadership effectiveness", Journal of Leadership \& Organizational Studies, Vol. 16, No. 1, pp. 38-47.

[12] Ryan, J. and Tipu, S. (2013), "Leadership effects on innovation propensity: a two-factor full range leadership model", Journal of Business Research, Vol. 66, No. 10, pp. 2116-2129.

[13] Talim, B. (2012), "Creating a meaningful planned change", Procedia Economics and Finance, Vol. 4, pp. 140-148.

[14] Armenakis, A.A., Harris, S.G. and Mossholder, K.W. (1993), "Creating readiness for organizational change", Human Relations, Vol. 46, No. 6, pp. 681-703

[15] Ghazisaeidi M, Ahmadi M, Sadoughi F. 2013. An Assessment of Readiness for Pre-Implementation of Electronic Health Record in Iran: 
European Journal of Business and Management Research www.ejbmr.org

A Practical Approach to Implementation in general and Teaching Hospitals. Acta Med Iran: 52(7):533-544.

[16] Smelcer JB, Jacobs HM, Kantrovich L. 2009. Usability of Electronic Medical Records. J Usability Stud: 4(2):70-84.

[17] Sikh, G. 2011. Analysis of attitudes and behaviours of employees towards organizational change. International Journal of Human Resource Management and Research, Vol. 1 No. 1, pp. 1-13. 